\title{
Predictors of gaming disorder in children and adolescents: a school-based study
}

\author{
Felipe de M. Ferreira, ${ }^{1,2 *}$ iD Beatriz B. Bambini, ${ }^{1 *}$ Gabriela K. Tonsig, ${ }^{1}$ Lais Fonseca, ${ }^{1,2}$
} Felipe A. Picon, ${ }^{2,3,4}$ Pedro M. Pan, ${ }^{1,2,5}$ (iD Giovanni A. Salum, ${ }^{2,6}$ Andrea Jackowski, ${ }^{1,2}$ Eurípedes C. Miguel, ${ }^{2,7}$ Luis A. Rohde, ${ }^{2,6}$ Rodrigo A. Bressan, ${ }^{1,2,5}$ Ary Gadelha ${ }^{1,2,5}$

\footnotetext{
${ }^{1}$ Laboratório Interdisciplinar de Neurociências Clínicas (LiNC), Universidade Federal de São Paulo (UNIFESP), São Paulo, SP, Brazil.

${ }^{2}$ Instituto Nacional de Psiquiatria do Desenvolvimento (INPD), São Paulo, SP, Brazil. ${ }^{3}$ Departamento de Psiquiatria, Universidade Federal do Rio Grande do Sul (UFRGS), Porto Alegre, RS, Brazil. ${ }^{4}$ Grupo de Estudos sobre Adições Tecnológicas (GEAT), Porto Alegre, RS, Brazil. ${ }^{5}$ Instituto Ame Sua Mente, São Paulo, SP, Brazil. ${ }^{6}$ Serviço de Psiquiatria da Infância e Adolescência, Hospital de Clínicas de Porto Alegre (HCPA), UFRGS, Porto Alegre, RS, Brazil. ${ }^{7}$ Instituto de Psiquiatria, Faculdade de Medicina, Universidade de São Paulo (USP), São Paulo, SP, Brazil. * These authors have contributed equally to this manuscript.
}

\begin{abstract}
Objective: To determine whether psychiatric and gaming pattern variables are associated with gaming disorder in a school-based sample.

Methods: We analyzed data from the Brazilian High-Risk Cohort for Psychiatric Disorders, a community sample aged 10 to 18 , using questionnaires on gaming use patterns. We applied the Gaming Addiction Scale to diagnose gaming disorder and the Development and Well-Being Behavior Assessment for other diagnoses.

Results: Out of 407 subjects, 83 (20.4\%) fulfilled the criteria for gaming disorder. More role-playing game players were diagnosed with gaming disorder that any other genre. Gaming disorder rates increased proportionally to the number of genres played. Playing online, being diagnosed with a mental disorder, and more hours of non-stop gaming were associated with higher rates of gaming disorder. When all variables (including age and gender) were considered in a logistic regression model, the number of genres played, the number of non-stop hours, the proportion of online games, and having a diagnosed mental disorder emerged as significant predictors of gaming disorder.

Conclusion: Each variable seems to add further risk of gaming disorder among children and adolescents. Monitoring the length of gaming sessions, the number and type of genres played, time spent gaming online, and behavior changes may help parents or guardians identify unhealthy patterns of gaming behavior.
\end{abstract}

Keywords: Gaming disorder; game genres; online games; predictors; gaming session; mental disorders

\section{Introduction}

The gaming industry has grown remarkably since the first video games emerged in the 1970s. Their variety and accessibility have further expanded since the introduction of the Internet, which has led to concern about possible negative effects on children and adolescents. ${ }^{1}$

Several factors create an attractive gaming environment: incitement of curiosity, long-term concentration on the narrative, rewards or punishments, control over the virtual world, and empathy with the characters. ${ }^{2}$ Online gaming offers live interaction and competition with other players - features that could induce compulsive behavior. ${ }^{3}$

The ICD-11 (which will come into effect in 2022) characterizes gaming disorder (GD) as the lack of control when gaming, regardless of negative consequences. ${ }^{4}$ The DSM-5 introduced a diagnosis for internet gaming

Correspondence: Felipe Macedo, Rua Pedro de Toledo, 669, Vila Clementino, 04039-032, São Paulo, SP, Brazil.

E-mail: fdemacedof@gmail.com

Submitted Mar 17 2020, accepted May 16 2020, Epub Aug 032020. disorder (IGD) based on persistent and intense internet gaming. ${ }^{5}$ Studies have identified decreased happiness and neurobiological, social and psychological dysfunction as risk factors for IGD. ${ }^{6,7}$ IGD in youth has been linked to mental health and sleeping disorders, altered cognition and social impairment. ${ }^{8,9}$

Identifying groups susceptible to GD may be useful for understanding risk factors and developing prevention strategies. We hope to determine whether gender, mental disorders, genre preference, and online gaming patterns differ in children and adolescents with and without GD.

\section{Methods}

We analyzed data from a subsample of the Brazilian HighRisk Cohort for Psychiatric Disorders, a community-based

How to cite this article: Ferreira FM, Bambini BB, Tonsig GK, Fonseca L, Picon FA, Pan PM, et al. Predictors of gaming disorder in children and adolescents: a school-based study. Braz J Psychiatry. 2021;43:289-292. http://dx.doi.org/10.1590/1516-4446-20200964 
study designed to assess the trajectory of mental health problems in youth 10 to 18 years of age. The original sample included students from 57 schools in São Paulo and Porto Alegre, both large Brazilian urban centers. ${ }^{10}$ In 8,012 families $(9,937$ children), the biological parents were screened regarding family history of mental health problems. From this pool, the Cohort was created by combining two strata $(n=2,511)$. The first stratum included a sample of randomly selected subjects, the "random group" ( $n=958)$. The second stratum, the "high-risk group" $(n=1,553)$, included youth at risk for psychopathology, who were selected using a validated prioritization algorithm. ${ }^{10}$ From this pool of 2,511 individuals, a subsample of 750 agreed to participate in a neuroimaging and blood biomarker study. Of these, 407 agreed to answer a questionnaire about gaming behavior, which was applied during the 3-year follow-up.

The Gaming Addiction Scale (GAS) was administered and participants answered questions about the number of hours they spend gaming (total and nonstop sessions) and the types of games they prefer. ${ }^{10}$ The GAS assesses the use of games and was conceptually based on DSM-IV criteria for pathological gambling. Total scores range from 7 to 35 . The GAS covers the DSM-5 IGD criteria more completely than other scales. ${ }^{11}$ Participants who scored 3 or more on at least four questions were considered to have fulfilled the criteria for GD. ${ }^{12}$

Six genre categories were included: first person shooters, action (adventure, sports or racing), role-playing games (RPG) (both offline and online), social network games (i.e., browser games played through social networks), puzzles/simulators, and other (e.g., board games and trivia games). ${ }^{13}$ We collected data on the number of genres played by each participant. GD frequency was calculated for individual genres and the number of genres played. Participants were also asked the proportion of time they played online with other people. Possible answers included never, less than half, half, and more than a half, and we calculated the GD frequency for each answer.

The Development and Well-Being Assessment was used to confirm the presence of mental disorders. ${ }^{14}$ In our analysis this was considered a binary variable, i.e. yes or no to the presence of any mental disorder(s).

\section{Statistics}

We compared total GAS scores between players and non-players of each genre with $t$-tests. We used analysis of variance to verify whether playing online affected GAS scores. A $t$-test was used to compare gaming session length between participants who did and did not fulfill GD criteria. Logistic regression of the following factors was used to determine predictors of GD: genre type, mental disorder status, age, number of genres played, gaming session length, and proportion of time spent playing online. The sample's normality was confirmed through Shapiro-Wilk and Kolmogorov-Smirnov tests. Paired Pearson correlations between all variables were calculated and did not exceed 0.35 .

\section{Ethics statement}

All parents provided written informed consent and children provided verbal assent. The ethics committees of all universities involved in the cohort approved the project.

\section{Results}

A total of 407 students were included in our study $(60.93 \%$ male, mean age $=14.32$, standard deviation $[S D]=1.86$, median age $=14.18$ ). GAS scores ranged from 7 to 32 (median $=11)$, and $83(20.4 \%)$ participants fulfilled the criteria for GD. Only $10(2.5 \%)$ participants denied playing video games in the six months prior to the interview.

\section{Gender}

GAS scores were significantly higher $(t=4.482$, degrees of freedom [df] $=385.3, p<0.01$ ) among boys $(13.68$, $\mathrm{SD}=5.66)$ than girls $(11.4, \mathrm{SD}=4.54)$. The $\mathrm{GD}$ criteria were met by $18(11.3 \%)$ girls and $65(26.2 \%)$ boys. The majority $(78.3 \%)$ of participants who were diagnosed with $\mathrm{GD}$ were male. The gaming sessions of boys were also longer $(2.2$ hours, $S D=1.7)$ than those of girls ( 1.3 hours $\mathrm{SD}=1.3 ; t=5.7, \mathrm{df}=394.8, \mathrm{p}<0.01)$. Although 78 $(31.5 \%)$ boys played online at least half of the time, only $18(11.3 \%)$ girls did so.

\section{Psychopathology}

A total of $36.9 \%$ ( $n=150)$ participants were diagnosed with any mental disorder, and these individuals has higher GAS scores $(14.4, S D=5.99)$ than those without mental disorders $(11.85, \mathrm{SD}=4.72 ; t=-4.4639$, df $=257.09$, $p<0.01$ ). Among the participants who met the criteria for GD, $51(61.5 \%)$ had another mental disorder.

\section{Gaming genres}

Action was the most commonly played genre $(75.82 \%)$, followed by first person shooters $(56.48 \%)$. The least played genre was RPG (24.4\%). There was a large overlap between genres: only $56(13.8 \%)$ of the participants played a single genre, whereas $244(60.5 \%)$ played three genres or more. Only those who played RPG, first person shooters and puzzle/simulator games scored significantly higher on the GAS. GD frequency was higher among RPG players (33.64\%). The rate of compulsive players increased with the number of genres played (Table 1), reaching $37.9 \%$ ( 11 of 29 participants) when more than five genres were reported.

\section{Online gaming}

A total of $52.3 \%$ of the participants did not play online. Of those who did, $24.1 \%$ played online less than half the time, $14.5 \%$ half the time, and $9.1 \%$ more than half the time/always. GAS scores differed according to proportion of time played online $(F=15.45, d f=3, p<0.01)$ (Figure 1). GD was more frequent among those who played online more frequently: GD was diagnosed in 
Table 1 Gaming disorder frequency according to genre

\begin{tabular}{|c|c|c|c|c|c|c|}
\hline & FPS & Action & RPG & Puzzle/simulators & Social network & Other \\
\hline $\begin{array}{l}\text { Total, } \mathrm{n} \\
\text { GD frequency, n (\%) }\end{array}$ & $\begin{array}{l}259 \\
65(25.1 \%)\end{array}$ & $\begin{array}{c}345 \\
75(21.7 \%)\end{array}$ & $\begin{array}{c}113 \\
39(34.5 \%)\end{array}$ & $\begin{array}{c}245 \\
60(24.5 \%)\end{array}$ & $\begin{array}{c}151 \\
38(25.2 \%)\end{array}$ & $\begin{array}{c}36 \\
10(27.8 \%\end{array}$ \\
\hline $\begin{array}{l}\text { Number of genres played } \\
\text { Total,* } \mathrm{n} \\
\text { GD frequency, } \mathrm{n}(\%)\end{array}$ & $\begin{array}{l}1 \text { genre } \\
56 \\
4(7.1 \%)\end{array}$ & $\begin{array}{c}2 \text { genres } \\
103 \\
10(9.7 \%)\end{array}$ & $\begin{array}{c}3 \text { genres } \\
133 \\
29(21.8 \%)\end{array}$ & $\begin{array}{c}4 \text { genres } \\
82 \\
26(31.7 \%)\end{array}$ & $\begin{array}{c}5 \text { genres } \\
26 \\
9(34.6 \%)\end{array}$ & $\begin{array}{c}\text { All genres } \\
3 \\
2(66.7 \%)\end{array}$ \\
\hline
\end{tabular}

* The number of individuals that play at least one game genre (FPS, action, RPG, puzzle/simulators, social network and/or other), categorized according to the total number of genres played. Each player was included in only one of the six categories $(1$ genre, 2 genres, 3 genres, 4 genres, 5 genres or all genres). We determined the GD frequency within each category.

$\mathrm{FPS}$ = first person shooter; GD = gaming disorder; RPG = role-playing game.

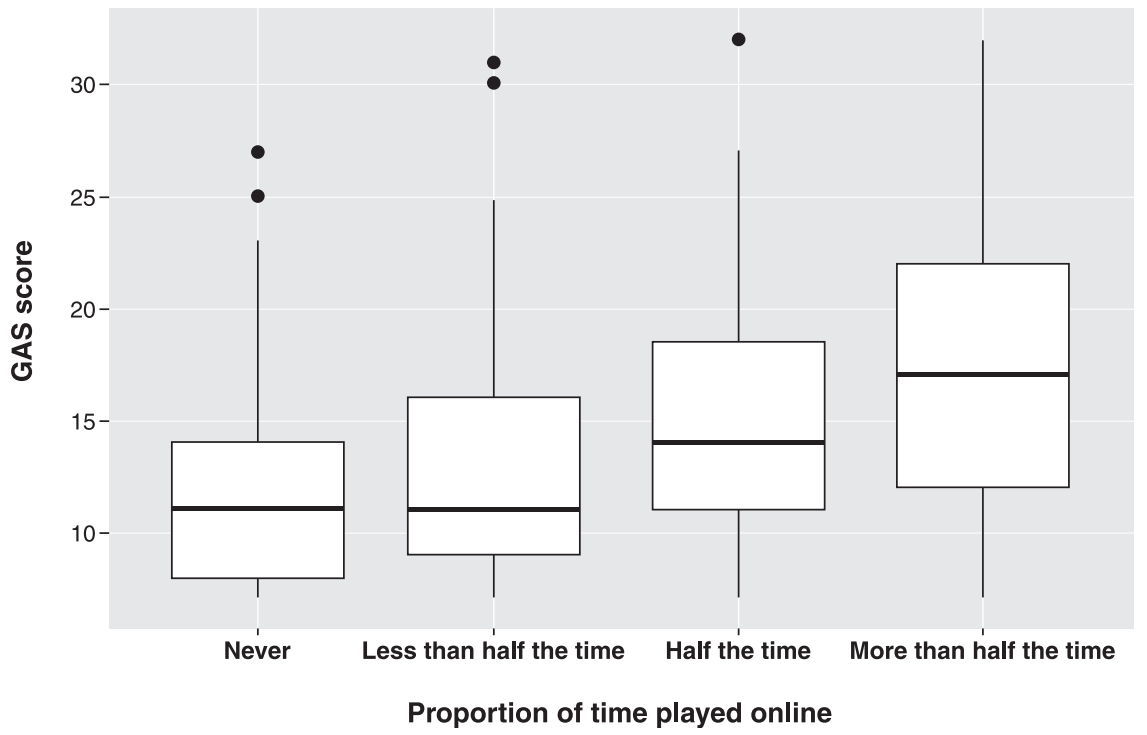

Figure 1 GAS score and proportion of time spent playing video games online. GAS = Gaming Addiction Scale.

$12.7 \%$ of participants who did not play online and in $49.7 \%$ of those who played online more than half of the time. Individuals who played online (2.26 hours) had a higher mean gaming session length than those who did not (1.47 hours).

\section{Gaming session length}

Participants with GD had longer non-stop gaming sessions (2.64 hours, $S D=2.17$ ) than those without it (1.65 hours, $\mathrm{SD}=1.34 ; t=-3.98, \mathrm{df}=98.56, \mathrm{p}<0.01$ ). The Pearson correlation between GAS score and length of gaming session was significant $(0.36, \mathrm{Cl} 0.28-0.45)$.

\section{Logistic regression}

The number of genres played $(<0.001$, Est. $=0.43)$, the number of non-stop hours $(<0.05$, Est. $=0.2)$, the proportion of time played online $(<0.05$, Est. $=0.31)$, and the presence of any mental disorder $(<0.001$, Est. $=1.4)$ were significant predictors of GD in the logistic regression model.

\section{Discussion}

Compulsiveness was most frequent among RPG players. A main attraction of the RPG genre is character development as the game progresses. Such a process demands time and involves acquiring skills and achieving rewards. The player experiences the character's achievements as if they were his own, which could enhance the classic reinforcement mechanism responsible for addictive behaviors and could result in more hours spent gaming. To best of our knowledge, no study has investigated the relationship between genre preference and GD.

The proportion of time spent playing online was a significant predictor of GD, reinforcing the idea that online interaction increases the risk of addictive behavior. Previous studies have reported that online gaming is generally associated with a community of players. While online, players may find people with similar interests and spend more time gaming together. ${ }^{15}$ However, other authors have reported that online gaming could also help alleviate psychological distress by establishing social relationships. ${ }^{16}$

As expected, boys had higher GAS scores and a higher GD rate than girls. Previous research has demonstrated that single men have higher scores on scales assessing GD symptoms. ${ }^{17}$ This may reflect a male orientation toward activities that involve aggressive and/or competitive content. ${ }^{18,19}$

The most significant predictor of GD was the presence of mental disorders. Previous studies have found that GD 
is associated with depression, anxiety, attention-deficit/ hyperactivity disorder and social phobia/anxiety. ${ }^{7,8}$ It is unclear whether playing is a risk factor for developing other mental illnesses or a coping strategy for dealing with them.

In terms of limitations, we relied on self-report instruments, which may have underestimated time spent playing. We could not rule out the effects of specific genres, combinations of genres, or combinations of online playing and genres. In addition, the "social network games" category included any games featured on social networks, which could have resulted in a mixture of genres. Finally, considering the cross-sectional design of our study, we could not assess gaming frequency over a specific time frame (e.g. one week) or investigate the directionality of the associations.

In conclusion, GD is a disorder associated with relevant personal and social impairment. Targeting the duration of gaming sessions, especially online sessions, may reduce this novel addiction in youth. Our study pointed to an association between GD and RPG, indicating that this genre could also help define a risk group. Finally, the presence of mental disorders was the most significant predictor of GD. We hope our findings can help clarify risk factors, determine susceptible groups, and assist in the development of GD prevention strategies in young people.

\section{Acknowledgements}

$R A B$ has received research grants from the governmental funding research agencies Coordenação de Aperfeiçoamento de Pessoal de Nível Superior (CAPES), Conselho Nacional de Desenvolvimento Científico e Tecnológico (CNPq) and Fundação de Amparo à Pesquisa do Estado de São Paulo (FAPESP; grants 2016/022465 and 2011/ 50740-5).

\section{Disclosure}

LAR has been on the speakers' bureau and/or consulted for Eli-Lilly, Janssen-Cilag, Medice, Novartis, and Shire; has received royalties from Oxford Press and ArtMed; and has received travel awards to participate in the 2016 AACAP and 2018 APA meetings from Novartis and Shire. The ADHD and Child Bipolar Disorders Outpatient Programs chaired by him has received unrestricted educational/research support from Eli-Lilly, Janssen-Cilag, Novartis, and Shire. RAB has received research grants from Janssen; and has participated in speaker bureaus for Janssen and Sanofi-Aventis. AG has participated in advisory boards for Janssen and Daiichi Sankyo; and has received fees as a speaker for Daichii-Sankyo, Ache, Janssen, and Torrent. The other authors report no conflicts of interest.

\section{References}

1 Gentile DA, Bailey K, Bavelier D, Brockmyer JF, Cash H, Coyne SM, et al. Internet gaming disorder in children and adolescents. Pediatrics. 2017;140 Suppl. 2:S81-5.
2 Denisova A, Guckelsberger C, Zendle D. Challenge in digital games: towards developing a measurement tool. In: $\mathrm{CHI} 17$ Extended Abstracts; May 06-11, 2017; Denver, USA. http://research.gold.ac.uk/ 21744/1/denisova_chi2017_challenge.pdf

3 Paulus FW, Ohmann S, von Gontard A, Popow C. Internet gaming disorder in children and adolescents: a systematic review. Dev Med Child Neurol. 2018;60:645-59.

4 World Health Organization (WHO). ICD-11 for Mortality and Morbidity Statistics (ICD-11 MMS). 2018 version [Internet]. [cited 2010 Jun 18]. icd.who.int/browse11//-m/en

5 American Psychiatric Association. Diagnostic and Statistical Manual of Mental Disorders, Fifth Edition (DSM-5). Arlington: American Psychiatric Publishing; 2013.

6 Muller KW, Dreier M, Wolfling K. Excessive and addictive use of the internet - prevalence, related contents, predictors, and psychological consequences. In: Reinecke L, Oliver MB, editors. The Routledge handbook of media use and well-being. New York: Routledge, Taylor and Francis; 2016. p. 223-36.

7 Laffan DA, Greaneya J, Barton H, Kaye LK. The relationships between the structural video game characteristics, video game engagement and happiness among individuals who play video games. Comput Human Behav. 2016;65:544-9.

8 Andreassen CS, Billieux J, Griffiths MD, Kuss DJ, Demetrovics Z, Mazzoni E, et al. The relationship between addictive use of social media and video games and symptoms of psychiatric disorders: a large-scale cross-sectional study. Psychol Addict Behav. 2016;30: 252-62.

9 González-Bueso V, Santamaría JJ, Fernández D, Merino L, Montero E, Ribas J. Association between internet gaming disorder or pathological video-game use and comorbid psychopathology: a comprehensive review. Int J Environ Res Public Health. 2018;15:668.

10 Salum GA, Gadelha A, Pan PM, Moriyama TS, Graeff-Martins AS, Tamanaha AC, et al. High risk cohort study for psychiatric disorders in childhood: rationale, design, methods and preliminary results. Int $\mathrm{J}$ Methods Psychiatr Res. 2015;24:58-73.

11 Petry NM, Rehbein F, Gentile DA, Lemmens JS, Rumpf HJ, Mossle $\mathrm{T}$, et al. An international consensus for assessing internet gaming disorder using the new DSM-5 approach. Addiction. 2014; 109:1399-406.

$12 \mathrm{Koo} \mathrm{HJ}$, Han DH, Park SY, Kwon JH. The structured clinical interview for DSM-5 Internet gaming disorder: development and validation for diagnosing IGD in adolescents. Psychiatry Investig. 2017;14:21-9.

13 Braun B, Stopfer JM, Müller KW, Beutel M, Egloff B. Personality and video gaming: comparing regular gamers, non-gamers, and gaming addicts and differentiating between game genres. Comput Human Behav. 2016;55:406-12.

14 Goodman R, Ford T, Richards H, Gatward R, Meltzer H. The Development and well-being assessment: description and initial validation of an integrated assessment of child and adolescent psychopathology. J Child Psychol Psychiatry. 2000;41:645-55.

$15 \mathrm{Kim} \mathrm{S}$, Jiyoun $\mathrm{H}$, Kim J. Detecting personality unobtrusively from users' online and offline workplace behaviors. In: CHI EA '18: Extended Abstracts of the $2018 \mathrm{CHI}$ Conference on Human Factors in Computing Systems; April 2018. Paper No.: LBW515. p. 1-6. dl. acm.org/doi/10.1145/3170427.3188566

16 Andreassen CS, Billieux J, Griffiths MD, Kuss DJ, Demetrovics Z, Mazzoni E, et al. The relationship between addictive use of social media and video games and symptoms of psychiatric disorders: a large-scale cross-sectional study. Psychol Addict Behav. 2016;30: 252-62.

17 Dorgan T. Video game engagement: gender differences, preferred mode of play and problem solving [Internet]. 2018 [cited 2020 Jun 18]. https://esource.dbs.ie/bitstream/handle/10788/3421/ba_dorgan_t_2018. pdf?sequence $=1$ \&isAllowed $=y$

18 Reyes MES, Davis RD, Lim RAN, Lim KRS, Paulino RF, Carandang $\mathrm{RMD}$, et al. Five-factor model traits as predictors of pathological gaming among selected Filipino gamers. Psychol Stud. 2019;64: 213-20.

19 Zajac K, Ginley MK, Chang R, Petry NM. Treatments for Internet gaming disorder and Internet addiction: a systematic review. Psychol Addict Behav. 2017;31:979-94. 